\title{
The Research on safety Evaluation Theory of Hoisting Machinery Based on Sustainable Development
}

\author{
Zheng-qiu Huang ${ }^{1,{ }^{*}}$, Li-xin Ren ${ }^{1}$,Yao-ting Tong ${ }^{1}$, Wei-ping Ouyang ${ }^{1}$ \\ ${ }^{1}$ Shanghai Institute of Special Equipment Inspection and Technical Research, 200062, Shanghai
}

\begin{abstract}
This paper introduces the purpose and significance of safety evaluation of hoisting machinery, summarizes various evaluation method, and discusses the advantages and disadvantages of various safety evaluation methods, analyzes the current situation of safety evaluation of hoisting machinery in China, and puts forward corresponding suggestions on energy saving and emission reduction of hoisting machinery through the evaluation.
\end{abstract}

\section{Preface}

Hoisting machinery is an indispensable equipment in modern industrial production, which is widely used in lifting, transportation, loading and unloading, installation and personnel transportation of all kinds of materials. In recent years, the implementation and completion of major projects in China cannot be separated from the figure of large lifting machinery, such as the construction of Hong Kong-Zhuhai-Macao Bridge and the manufacture of large military equipment. Obviously, large hoisting machinery has become an important index to measure the level of scientific and technological development of a country. However, because the large hoisting machinery has the characteristics of high parameters (large lifting weight, working range, lifting height and so on), the accident risk of hoisting machinery is high, and the accident consequences caused by failure are great. Therefore, the key points of special equipment safety supervision and energy saving supervision issued by the Special equipment Bureau of the State Administration of Market Supervision and Administration of Market Supervision also explicitly require strengthening the safety risk analysis of hoisting machinery, The latest "rules for periodic inspection of lifting appliances" also requires that when the service life of lifting appliances reaches more than 15 years, or they are in strong wind area or serious corrosive environment for a long time, as well as in the case of high frequency of use, safety assessment should be carried out. through risk warning and taking targeted measures to urge enterprises to implement the main responsibility and prevent accidents. It can be said that the safety of hoisting machinery has become an urgent problem to be solved.

To strengthen supervision and reduce accidents, China has promulgated a lot of standards and regulations, even so, the frequency of hoisting machinery safety accidents is still high. On the one hand, with the increase of the service age of the crane, the structural performance degrades and the bearing capacity decreases, the reliability and safety of the crane cannot be guaranteed, and the structural damage will often lead to large property and personal losses. On the other hand, there is still a lack of a set of unified standards for crane safety assessment in our country. The special equipment supervision department urgently hopes that the technical institutions can study and formulate the relevant evaluation standards in order to comprehensively and correctly evaluate the in-service cranes, enhance the safe use, and fill in the gaps in this field. At the same time, it can also provide technical basis for enterprises to master the safety situation of cranes and do a good job of maintenance plan in advance. Therefore, it is of great engineering value and practical significance to explore a set of scientific and reasonable safety assessment methods.

\section{Safety evalution}

Safety assessment (also known as risk assessment) [1] is to identify and analyze the dangerous and harmful factors existing in engineering and system by using the principle and method of safety system engineering in order to realize the safety of engineering and system, to judge the possibility and severity of engineering and system accidents and acute occupational hazards, and to put forward some safety countermeasures and suggestions. So as to provide scientific basis for engineering and system to formulate preventive measures and management decisions. Crane safety evaluation is to evaluate the overall safety situation of cranes, qualitatively or quantitatively analyze the risk indexes of related main metal structures, operating institutions, electrical control systems and safety protection devices, find out the possible faults and hidden dangers, and take corresponding measures to eliminate faults and reduce the degree of harm. 


\section{Classification of safety evaluation methods}

Safety evaluation methods [2] can be divided into the following categories: qualitative evaluation method, probability analysis method, intelligent evaluation method, fuzzy evaluation method and so on. As can be seen from table 1 , the qualitative evaluation method is very simple and operational. By collecting historical data, the relevant risk indicators of the evaluation object are listed as tables, the judgment and opinions of the relevant experts are consulted, these opinions are statistically, summarized, the evaluation results are obtained, and the decision-making scheme is revised. Qualitative evaluation method can make a reasonable evaluation of uncertain factors and factors that are difficult to carry out quantitative analysis, but the method is subjective. However, the evaluation index of metal structure in the safety assessment of hoisting machinery can be quantitatively analyzed, so this method is not the optimal choice.

Bayesian analysis method is a common method in probability evaluation. Bayesian analysis method is the basis of Bayesian learning. It provides a method to calculate the probability of hypothesis. This method is based on the prior probability of hypothesis, the probability of different data observed under given hypothesis and the observed data itself. The method is to synthesize the prior information about the unknown parameters with the sample information, then get the posterior information according to the Bayesian formula, and then infer the unknown parameters according to the posterior information。

Bayes theorem:

Let $A_{1}, A_{2}, \ldots, A_{n}$ be disjoint events,

that is $\mathrm{P}\left(\mathrm{A}_{i} \cap \mathrm{A}_{\mathrm{j}}\right)=0, i \neq \mathrm{j}$; And $\mathrm{P}\left(\mathrm{A}_{1} \cup \mathrm{A}_{2} \cup \ldots \cup \mathrm{A}_{m}\right)$, set up necessary events

$\sigma=\mathrm{A}_{1} \cup \mathrm{A}_{2} \cup \ldots \cup \mathrm{A}_{m}, \mathrm{P}(\sigma)=1$.

So we have the formula:

$$
P(B)=P(B / \sigma)=\sum_{j=1}^{\mathrm{m}} P\left(B / A_{i}\right) P\left(A_{i}\right)
$$

The inevitable event $\sigma$ is divided into $m$ disjoint sub events, The conditional probability of event $\mathrm{B}$ is the sum of the conditional probabilities of event $B$ given each sub event $A_{j}(j=1,2, \ldots, m)$. Then, given event $B(P(B)>0)$, the conditional probability of event $A_{k}$ can be written as:

$$
\begin{gathered}
P\left(A_{k} / B\right)=\frac{P\left(B / A_{k}\right) P\left(A_{k}\right)}{P(B)}=\frac{P\left(B / A_{k}\right) P\left(A_{k}\right)}{\sum_{j=1}^{m} P\left(B / A_{j}\right)}=\frac{P\left(B / A_{k}\right) P\left(A_{k}\right)}{\sum_{j=1}^{m} P\left(B / A_{j}\right) P\left(A_{j}\right)} \\
k=1,2, \ldots m
\end{gathered}
$$

Fuzzy Evaluation method is a scientific method using fuzzy matrix operation, for multiple subsystems and multi-factor comprehensive evaluation. It is characterized by the establishment of mathematical model, the evaluation effect of multi-factor and hierarchical complex problems is better, and it is difficult to replace other mathematical branches and models, but it is vulnerable to the influence of subjective factors of evaluators, and the determination method of membership function needs to be further studied. KellerA.Z et al., who first applied the fuzzy evaluation method to the safety assessment of cranes.

Intelligent evaluation method needs a certain amount of training samples, which can avoid the calculation of index weight, but the number of samples is too large and the training complexity increases. In addition, when the learning samples change, it is necessary to optimize the discriminant network structure, otherwise the evaluation results are not reliable. The most popular intelligent evaluation method is BP netural network. BP neural network comprehensive evaluation method is an interactive evaluation method, which can not only avoid the inaccuracy of artificial weight calculation, but also avoid the complexity of solving the correlation coefficient. It can also comprehensively evaluate a large number of cases with more indexes. It can continuously modify the index weight according to the user's expected output until the user is satisfied. Therefore, generally speaking, the results of artificial neural network evaluation method will be more in line with the actual situation. BP neural network is a typical multi-layer forward neural network, which is composed of input layer, hidden layer and output layer. All layers are connected, and there is no interconnection between nodes in the same layer. The input layer node only acts as signal input, the output layer node acts as linear weighting, and the hidden layer node is responsible for the most important mathematical processing of information.

Table 1. Theoretical classification of safety assessment.

\begin{tabular}{|c|c|c|c|c|}
\hline Method classificaton & Method name & Method description & Advantages & Shortcomings \\
\hline $\begin{array}{c}\text { Qualitative } \\
\text { evaluation } \\
\text { method }\end{array}$ & $\begin{array}{c}\text { Safety check } \\
\text { form method, } \\
\text { expert meeting } \\
\text { method, Delphi } \\
\text { method }\end{array}$ & $\begin{array}{c}\text { According to } \\
\text { the expert } \\
\text { knowledge and } \\
\text { opinion to form the } \\
\text { evaluation } \\
\text { results. }\end{array}$ & $\begin{array}{c}\text { It reflects the } \\
\text { knowledge of } \\
\text { experts and is } \\
\text { simple to } \\
\text { operate. }\end{array}$ & $\begin{array}{c}\text { There is a strong } \\
\text { subjectivity and there } \\
\text { is a need to deal with } \\
\text { the issue of } \\
\text { disagreements } \\
\text { among experts. }\end{array}$ \\
\hline $\begin{array}{c}\text { Probability } \\
\text { evaluation } \\
\text { method }\end{array}$ & $\begin{array}{c}\text { Fault tree } \\
\text { method, Bayes } \\
\text { method, FSA, } \\
\text { etc. }\end{array}$ & $\begin{array}{c}\text { method is used } \\
\text { to describe the } \\
\text { mechanism of } \\
\text { the accident } \\
\text { and infer the } \\
\text { evaluation } \\
\text { results. }\end{array}$ & $\begin{array}{c}\text { Can achieve } \\
\text { qualitative or } \\
\text { quantitative security } \\
\text { assesment. The FSA } \\
\text { method can also } \\
\text { analyze the safety } \\
\text { investment and } \\
\text { safety benefit. }\end{array}$ & $\begin{array}{c}\text { It takes a lot of } \\
\text { time and effort } \\
\text { to carry out data } \\
\text { statistics and } \\
\text { probability } \\
\text { calculation. }\end{array}$ \\
\hline
\end{tabular}




\begin{tabular}{|c|c|c|c|c|}
\hline $\begin{array}{c}\text { Intelligent } \\
\text { evaluation } \\
\text { method }\end{array}$ & $\begin{array}{c}\text { BP neural } \\
\text { network [3-4], } \\
\text { support vector } \\
\text { machine [5], } \\
\text { etc. }\end{array}$ & $\begin{array}{c}\text { Through the } \\
\text { Training samples, the } \\
\text { function is established } \\
\text { to } \\
\text { compare the } \\
\text { objects to be } \\
\text { evaluated with } \\
\text { the existing } \\
\text { samples, and } \\
\text { the evaluation results } \\
\text { are determined. }\end{array}$ & $\begin{array}{l}\text { The evaluation } \\
\text { process is not } \\
\text { affected by } \\
\text { human factors } \\
\text { and has strong } \\
\text { objectivity. }\end{array}$ & $\begin{array}{l}\text { A large number } \\
\text { of effective } \\
\text { evaluation } \\
\text { samples are } \\
\text { needed, } \\
\text { otherwise the } \\
\text { evaluation } \\
\text { results are not } \\
\text { reliable. }\end{array}$ \\
\hline $\begin{array}{c}\text { Fuzzy } \\
\text { evaluation } \\
\text { method }\end{array}$ & $\begin{array}{l}\text { Grey evaluation } \\
\text { method [6], fuzzy } \\
\text { comprehensive } \\
\text { evaluation } \\
\text { method [7], extension } \\
\text { evaluation method }\end{array}$ & $\begin{array}{l}\text { Through the } \\
\text { establishment of the } \\
\text { relationship between } \\
\text { the evaluation index } \\
\text { and the evaluation } \\
\text { standard, the security } \\
\text { level of the evaluation } \\
\text { object is } \\
\text { determined. }\end{array}$ & $\begin{array}{l}\text { It can solve the } \\
\text { problem of cognitive } \\
\text { uncertainty and is } \\
\text { suitable for dealing } \\
\text { with the evaluation } \\
\text { problem with fuzzy } \\
\text { attributes. }\end{array}$ & $\begin{array}{l}\text { The determination } \\
\text { method of } \\
\text { membership } \\
\text { function needs to be } \\
\text { further studied. }\end{array}$ \\
\hline
\end{tabular}

\section{Present situation of crane safety evaluation in China}

The development of crane risk assessment system in China is in its infancy. Since the late 1990s, a small number of colleges and institutions have studied and practiced the theory, method and practical application of crane safety assessment. For example, Yang Chunni, Qiu Quan identified the dangerous sources of mobile cranes in 2014, and evaluated the risk accidents induced by specific dangerous sources through accident tree analysis [8]. Liu Jingzhi, Yin Chenbo used fuzzy theory method to evaluate the safety of gantry cranes in 2014 [9]. It is pointed out that there is no constant relationship between the weight and the evaluation value of the evaluation index, and the weight cannot be obtained from the evaluation value through the specific calculation formula, and the evaluation value of the index cannot be obtained from the weight. On this basis, the weight has the unity. However, because the matrix corresponding to the weight is fixed, there is a constant quantitative relationship between the other matrices, and at the same time, the comprehensive evaluation of multiple indicators is carried out, in this case, the weight is consistent. In the process of determining the specific weight, the single weight and the compound weight should be combined to consider. Taking gantry crane as an example, Chen Lei of Wuhan University of Science and Technology [10] expounds the establishment of risk assessment system from the aspects of metal structure strength, stiffness, stability and crack of gantry crane based on fuzzy analytic hierarchy process (AHP). Through a series of steps such as data acquisition, the safety factor of gantry crane is calculated and the risk range of gantry crane is determined. Although some progress has been made in recent years, there is still considerable room for further development, especially in the aspect of method innovation, which will be the main research direction of many experts and scholars. In fact, there are still shortcomings and defects in the existing research methods [11]. First of all, there are defects in the research method of crane safety evaluation method. The existing research results generally use case analysis method to study crane safety assessment, generally only for a specific type of crane case analysis, but whether this type of crane safety evaluation method is suitable for all types of crane safety evaluation is not involved, and there is a lack of comprehensiveness in the research methods and research objects. At the same time, in the existing research results, there is a lack of safety evaluation from the dual angle of crane enterprises and equipment. Second, in the current research results, it is said that the specific safety evaluation method adopted is a single evaluation method, such as a single analytic hierarchy process (AHP) or safety inspection table method, which inevitably exposes the shortcomings of these safety evaluation methods in the process of evaluation. Only through numerical calculation and hierarchical evaluation, the evaluation results actually have a certain one-sidedness. It should be possible to use a variety of safety evaluation methods to combine the model [12], in order to reflect the safety state of the crane more accurately and comprehensively.

\section{5 conclusion}

There are many large cranes in extended service in our country, if things go on like this, the safety situation is worrisome, which brings challenges to the stable operation of enterprises. The purpose of this paper is to classify and analyze the advantages and disadvantages of different evaluation methods, summarize the research status of crane safety evaluation methods at home and aboad, and put forward some suggestions and opinions on the shortcomings of the present situation: 1. The relationship between qualitative and quantitative, scientific safety evaluation of cranes will adopt comprehensive evaluation method, including qualitative and quantitative analysis, abandon the single evaluation method. 2. The relationship between universality and personality of evaluation methods, each crane has its special use requirements and use environment. When we formulate the evaluation method, we should not only pay 
attention to the commonness of the same type of equipment, but also pay attention to the personality of a single equipment, so that we can make a correct evaluation conclusion for each equipment.

\section{Acknowledgements}

I would like to express my sincere thanks to Shanghai Institute of special equipment supervision and inspection technology. With the help of my colleagues, I completed this paper.

Last my thanks would go to my beloved family for their loving considerations and great confidence in me all through these years. I also owe my sincere gratitude to my friends who gave me their help and time in listening to me and helping me work out my problems during the difficult course of the thesis.

\section{References}

1. Cai Xin, Guo Xingwen, Xu Jincai. Safety risk assessment of rural hydropower stations [M]. Science Press, 2015.

2. Li Aihua. Research on Safety Evaluation method of quayside Container Crane, Wuhan University of Technology [P], 2017.

3. Li Bo, Chen Dingfang, Tao Dexin, etc. Safety evaluation of crane based on artificial neural network $[\mathrm{J}]$. Lifting and transportation machinery, 2006 (9): 52 / 55.

4. He Yudong. Research on Safety Evaluation method of lifting Machinery based on Neural Network [D]. Nanchang University, 2012.

5. Su Gaoli, Deng Fangping. Model selection of support vector regression machine $[\mathrm{J}]$. Science and Technology Bulletin, 2006, 22 (2): 154158.

6. Chen Zhaofang, Zhang Qishan. Safety evaluation of gantry frame system of gantry crane based on grey theory and analytic hierarchy process $[\mathrm{J}]$. Journal of Fuzhou University, 2013 (3): 354 / 358.

7. Duan Zhishan, Cui Shanqiang. Application of fuzzy analytic hierarchy process in mechanical safety evaluation $[\mathrm{J}]$. Standardization and quality of Machinery Industry, 2007, (10): 38-39.

8. Yang Chunni, Qiu Quan, Zhang Xiao. Hazard Source Identification and Evaluation of Mobile Crane $[\mathrm{J} / \mathrm{OL}]$, Mechanical Engineering and Automation, 2014, (04): 224-226.

9. Liu Jingzhi, Yin Chenbo. Comprehensive assessment of safety status of gantry cranes based on fuzzy theory $[\mathrm{J}]$, Mechanical Manufacturing and Automation, 2014, 43 (01): 189-191.

10. Chen Lei. Study on damage mode and risk analysis method of door pedestal lifting machinery [D]. Wuhan University of Technology, 2013.

11. Qu Hui, Research on risk Assessment method of Crane [D]. Capital University of Economics and Trade, 2017.
12. Hu Jingbo, Ni Dajin, Li Quan. Application of Safety Evaluation method in Crane [J]. China Special equipment Safety, 2011 (8): 6 / 8 . 